\title{
Should Social Security Benefits Be Means Tested?
}

\section{Citation}

Feldstein, Martin. 1987. Should social security benefits be means tested? Journal of Political Economy 95(3): 468-484.

\section{Published Version}

http://dx.doi.org/10.1086/261467

\section{Permanent link}

http://nrs.harvard.edu/urn-3:HUL.InstRepos:2770498

\section{Terms of Use}

This article was downloaded from Harvard University's DASH repository, and is made available under the terms and conditions applicable to Other Posted Material, as set forth at http:// nrs.harvard.edu/urn-3:HUL.InstRepos:dash.current.terms-of-use\#LAA

\section{Share Your Story}

The Harvard community has made this article openly available.

Please share how this access benefits you. Submit a story.

\section{Accessibility}




\section{Should Social Security Benefits Be Means Tested?}

\section{Martin S. Feldstein}

Harvard Universty and National Bureau of Economic Research

Social security retirement benefits distort the saving decisions of workers who are rational enough to save for their future. Since the implicit rate of return in an unfunded social security program is less than the marginal product of capital, the resulting decline in saving causes a welfare loss. The present paper examines the conditions under which the welfare loss could be reduced by replacing the current universal social security program with a means-tested program that pays benefits only to those individuals with little or no other retirement income or assets.

Every society must solve the problem of supporting those individuals who become too old to work but have not made adequate provision for their own old age by saving when they were young. At the present time, the major industrial countries of the world have responded to this problem by creating social security programs that tax the working population and use the proceeds to provide a "universal" benefit to all retirees regardless of their financial condition.

This universal provision of social security benefits distorts the saving decisions of those workers who are rational enough to plan for the future. ${ }^{1}$ Since the implicit rate of return that taxpayers get on their

This research is part of the NBER Study of the Government Budget and the Private Economy. A more complete version of this paper with some numerical calculations is available as NBER Working Paper no. 1775 (Feldstein 1985b). I am grateful to Gilbert Metcalf for assistance with the calculations presented in this paper and for helpful discussions.

' For a discussion of the effect of promised retirement benefits on the savings of employees, see Feldstein (1974, 1982). Barro (1974, 1978) has discussed an interesting 
contributions to an unfunded social security program is less than the return available on savings invested in real capital, ${ }^{2}$ the individual who substitutes social security tax contributions for private savings suffers a welfare loss equal to the present value of the difference between the social security benefits and the amount of future income that the displaced savings would have earned. ${ }^{3}$ The basic problem of designing a social security program is to set the level of benefits (and the conditions for receiving benefits) in the way that best balances the desirability of protecting those who would otherwise make inadequate provisions for their old age against the cost of reduced saving by those who would otherwise save in a rational way. ${ }^{4}$

Friedman and others have suggested that the common system of universal eligibility for social security retirement benefits be replaced by a means-tested program that pays benefits only to those who lack assets or private pension income with which to finance postretirement

special case in which social security would have no effect on private saving. His conclusion requires that each individual act to maximize a utility function that has as one of its arguments the utility of his children and that the initial optimum behavior involve a positive amount of bequest. Of course, if everyone exhibited such rationality, there would be no need or justification for social security retirement benefits. The Barro conditions imply that social security does not change aggregate savings but some individuals may save more while others save less. Every individual's savings will be unchanged only if all individuals in each current and future generation are alike. Feldstein (1974) showed that the provision of social security benefits that are conditional on retirement can increase personal saving if the effect on saving of the induced increase in retirement outweighs the asset substitution effect. Sheshinski and Weiss (1981), Abel (1984), and Hubbard (1984) examine the implications of uncertain mortality and the absence of perfect annuity markets for the effect of social security on saving. Although there is a wide range of empirical estimates of the effect of social security on private saving, the bulk of the evidence appears to me to support the conclusion that increases in social security benefits reduce private saving. Studies supporting this conclusion include Blinder, Gordon, and Wise (1983) and Diamond and Hausman (1984). Those who find little or no effect of social security on savings include Munnell (1974) and Leimer and Lesnoy (1982).

${ }^{2}$ Samuelson's (1958) classic article showed that the implicit rate of return in an unfunded social security program is the rate of growth of aggregate wages. Samuelson considered the special case in which real wages per worker are constant, making the implicit rate of return on social security equal to the rate of growth of population.

${ }^{3}$ See Feldstein (in press). There is a further source of welfare loss to the rational individual if the social security program distorts labor supply either during working years (because the reward to working is reduced by the social security tax to an extent that is not compensated by the present value of future benefits) or at an age when retirement is possible (because potential benefits are reduced in whole or in part if the individual continues to work). See Danziger, Haverman, and Plotnick (1981) and Gustman and Steinmeier (1983) for recent discussions of these issues. The present analysis abstracts from these issues by assuming that the quantity of labor supplied and the age of retirement are both fixed.

${ }^{4}$ Feldstein (1985a) derives the optimal level of social security benefits in a universal social security program for two alternative specifications of imperfect foresight. For evidence on the significance of inadequate retirement savings, see Diamond (1977) and Kotlikoff, Spivak, and Summers (1982). 
consumption (see Friedman and Cohen 1972). Proponents of this change argue that limiting benefits only to those in financial need would reduce the size of the program and therefore the distortionary effect of the tax that is used to pay for it. It is also argued that, since rational savers would receive no benefits, their saving would be influenced only by the presumably modest amount of tax that they pay to finance the means-tested benefits. Despite the potential magnitude of the potential welfare gain, the choice between a universal and a means-tested program has not previously been the subject of theoretical analysis. That is the purpose of the present paper.

The analysis shows that there may be a strong case for a meanstested program but that it is more ambiguous than the casual analysis of Friedman and others would suggest. Although a means-tested program may be smaller in total size than a universal program, it does not necessarily produce greater social welfare even when the implicit return on social security taxes is substantially lower than the return available on private saving. The analysis in this paper shows two reasons why an optimal program of universal unconditional benefits would, under certain conditions, provide a higher level of social welfare than an optimal program of benefits conditioned by a means test.

The principal reason that a universal program may be superior is that a means-tested program with benefits set at the optimal level may induce some utility-maximizing workers to save nothing. Although their resulting consumption in retirement would then be less than they would have chosen without a social security program, the utility value of the extra consumption during working years more than offsets the reduced consumption during retirement. For these individuals, the means-tested program distorts savings and reduces individual utility by more than a universal program. If that group is large enough in the population, the universal program may be more desirable than a means-tested program.

It is also possible for the universal program to be superior even if the benefits in the alternative means-tested program are set at a level that does not induce any utility-maximizing workers to stop saving. This can occur if, in order to avoid inducing the utility maximizers to stop saving, the level of the means-tested benefits has to be set substantially lower than would otherwise be optimal. In this case, switching from a universal program to a means-tested program reduces the welfare of those who receive the constrained means-tested benefits by more than it increases the welfare of the nonrecipients.

In general, the choice between a means-tested program and a universal program depends on the parameters of the economy (in particular, the growth rates of income and population and the rate of return on real investments) and on the character and extent of eco- 
nomic shortsightedness among the working population. The nature of this dependence is examined in the present paper. The specific results in the very simple models examined here are of course only suggestive, but they do indicate some important qualitative properties that may be robust and suggest a framework for a more realistic detailed analysis.

The fact that the optimal choice between a means-tested program and a universal program depends on the character of the working population has an important general implication for the design of social security programs. It implies that, if the working population can be subdivided into groups that differ in the relevant parameters, it may be optimal to have a means-tested program for some groups and a universal program for others. The specific implications of this are discussed in the final section of the present paper.

\section{The Optimal Program in a Two-Class Society}

It is useful to begin the analysis with the simple case in which workers are either fully rational life cycle utility maximizers (or "cyclers" for short) or completely myopic individuals who always consume their entire net income ("myopes"). In this case, a means-tested program will produce higher social welfare than a universal program unless the level of means-tested benefits must be reduced substantially below the unconstrained optimum in order to prevent the cyclers from becoming nonsavers. Such a constraint may be binding because allowing the cyclers to become nonsavers would imply that the means-tested program was no longer selective but provided benefits to all retirees. The present section shows conditions under which such a constraint causes the universal program to be optimal. It also develops the basic structure of the analysis that is then extended in the next section to deal with a more heterogeneous population in which an optimal means-tested program will induce workers with limited myopia to stop saving.

The analysis is set in an overlapping generations model of the type developed by Samuelson (1958) and Diamond (1965). Individuals live for two periods, working in the first and being fully retired in the second. At time $t$ there are $L_{t}$ workers and $L_{t-1}$ retirees. The population grows at rate $n$ per period, implying that $L_{t}=(1+n) L_{t-1}$. Real wages per worker grow at rate $g$; thus $w_{t}=(1+g) w_{t-1}$. The rate of return on capital is $r$ per period.

It will simplify notation and interpretation in the analysis that follows if we define $x=(1+n)(1+g) /(1+r)$, the ratio of "one plus the growth rate of aggregate wages" to "one plus the rate of return on capital." Since the growth rate of aggregate wages is the implicit rate 
of return on social security, $x$ measures the efficiency of social security "saving" relative to savings invested in real capital.

A fraction $\mu$ of workers are myopes, who always consume their entire earnings during their working period. The remaining $1-\mu$ choose a saving level during their working years that maximizes lifetime utility, $u\left(C_{1 t}, C_{2, t+1}\right)$, where $C_{1 t}$ is consumption of workers in period $t$ and $C_{2, t+1}$ is consumption of retirees in period $t+1$. To be able to derive explicit values of consumption and utility, I shall assume that the lifetime utility function is $\log$-linear: $u\left(C_{1 t}, C_{2, t+1}\right)=\ln$ $C_{1 \imath}+\ln C_{2, t+1}$.

\section{A. A Universal Social Security Program}

When there is a universal social security program, the government levies a tax at rate $\theta$ on wages and uses the proceeds to finance concurrent benefits of $b_{t}^{u}$ to each retiree. The budget constraint of a universal social security program is $\theta w_{t} L_{t}=b_{t}^{u} L_{t-1}$, implying $b_{t}^{u}=(1+n) \theta w_{t}$.

Myopes consume $C_{1 \ell}=(1-\theta) w_{t}$ during their working years and $C_{2, t+1}=b_{t+1}^{u}$ when they are retired. Cyclers choose $C_{1 t}$ to maximize lifetime utility subject to the personal budget constraint $C_{2, t+1}=[(1$ $\left.-\theta) w_{t}-C_{1}\right](1+r)+b_{t+1}^{u}$. Optimal first-period consumption is therefore $C_{1 t}^{*}=0.5\left\{(1-\theta) w_{t}+\left[b_{t+1}^{u} /(1+r)\right]\right\}$ and the corresponding second-period consumption is $C_{2, t+1}^{*}=0.5\left[(1-\theta) w_{t}(1+r)+b_{t+1}^{u}\right]$. Using the government's budget constraint to write $b_{t+1}^{u}=(1+$ $n) \theta w_{t+1}=(1+n)(1+g) \theta w_{t}$ and recalling that $x=(1+n)(1+g) /(1$ $+r)$ is the efficiency of social security savings yields $C_{1 t}^{*}=0.5[(1-\theta)$ $+\theta x] w_{t}$ and $C_{2, t+1}^{*}=0.5[(1-\theta)+\theta x](1+r) w_{t}$.

Total utility at time $t$ is the sum of the utilities of the $L_{t}$ workers and the $L_{t-1}$ retirees. With a program of universal social security benefits, total utility at time $t$ is

$$
\begin{aligned}
W_{t}^{u}= & L_{t}\left[\mu \ln (1-\theta) w_{t}+(1-\mu) \ln 0.5(1-\theta+\theta x) w_{t}\right] \\
& +L_{t-1}\left[\mu \ln b_{t}^{u}+(1-\mu) \ln 0.5(1-\theta+\theta x)(1+r) w_{t-1}\right] .
\end{aligned}
$$

After substituting $b_{t}^{u}=(1+n) \theta w_{t}$ and $w_{t-1}=w_{t} /(1+g)$, it is possible to factor out $L_{t-1}$ and $\ln w_{t}$ and note that the value of $\theta$ that maximizes $W_{t}^{u}$ is the same as the value that maximizes total utility in any other period. ${ }^{5}$ I shall assume that the government wishes to choose $\theta$ to maximize this total utility. ${ }^{6}$

${ }^{5}$ Except for the initial period in which the program is started. In that period, retirees get windfall benefits that they never paid for. This is discussed in Feldstein (1985a, pp. 310-14).

${ }^{6}$ The government might instead choose $\theta$ to maximize the discounted value of utility in all years including the initial period. Ignoring the initial period is equivalent to assuming that the discount rate that the government applies in aggregating utilities is 
The first-order condition for the value $\theta *$ that maximizes total utility is

$$
\frac{\mu}{\theta^{*}}-\frac{(1+n) \mu}{1-\theta^{*}}-\frac{(2+n)(1-\mu)(1-x)}{1-(1-x) \theta^{*}}=0 .
$$

The qualitative implications of this condition are easily established by totally differentiating equation (2). It is easily shown in this way that $d \theta^{*} / d \mu>0, d \theta^{*} / d x>0$, and $d \theta^{*} / d n<0$. Before interpreting these, it is useful to derive also the effects of the parameters on the optimal value of the benefits per worker. Since $b_{t}^{u *}=\theta^{*}(1+n) w_{t}$, it follows immediately that $d b^{u * / d \mu}>0$ and $d b^{u * / d x}>0$. The sign of $d b^{u * / d n}$ is ambiguous and depends on the value of the other parameters.

It is easy to interpret these properties. Since an increase in the fraction of myopes increases the number of individuals who gain from a higher level of the universal benefit and decreases the number who lose, it raises the optimal benefit level $\left(d b^{u *} / d \mu>0\right)$ and therefore the corresponding tax rate $(d \theta * / d \mu>0)$. An increase in the relative efficiency of social security in comparison with real investment-that is, a rise in the ratio of the implicit rate of return on social security to the rate of return on real capital-reduces the cost to the cyclers of the compulsory social security program and therefore raises the optimal level of both benefits $\left(d b^{u * / d x}>0\right)$ and taxes $(d \theta * / d \mu>0)$. Finally, since an increase in the relative number of workers permits a given level of benefits to be achieved with a lower tax rate, $d \theta^{*} / d(1+$ $n)<0$.

\section{B. A Means-tested Social Security Program}

If the social security program is means tested and the level of taxes and benefits is set in a way that causes cyclers to save, benefits are paid only to retired myopes and the budget constraint linking the tax rate ( $\theta)$ to the level of means-tested benefits per beneficiary $\left(b^{m}\right)$ is $b_{t}^{m}=$ $\mu^{-1} \theta(1+n) w_{\iota}$ since only a fraction $\mu$ of retirees receive benefits. The behavior of the myopes is the same under a means-tested program as under the universal program. They consume their entire disposable income while working $\left(C_{1 t}=[1-\theta] w_{t}\right)$ and depend exclusively on the benefits to finance consumption during retirement $\left(C_{2, t+1}=b_{t+1}\right)$.

If the cyclers save, the level of means-tested benefits is irrelevant

relatively low so that the initial period gets litule weight or that the sum does not converge so that it is meaningful only to maximize the utility of a representative year. Feldstein (1985a) develops the discounted value and discusses these issues more explicitly. If the government's utility discount rate is less than $(1+g)(1+n)-1$, the discounted sum of utilities does not converge and the government must maximize the representative value of $W_{l}^{u}$. 
and their behavior is affected only by the tax. They maximize $u\left(C_{1 \ell}\right.$, $\left.C_{2, t+1}\right)=\ln C_{1 t}+\ln \left[(1-\theta) w_{t}-C_{1 t}\right](1+r)$ and therefore choose $C_{1 t}^{*}$ $=0.5(1-\theta) w_{t}$ and $C_{2, t+1}^{*}=0.5(1-\theta) w_{t}(1+r)$.

Cyclers will save if the utility that results from this combination of $C_{1 \ell}^{*}, C_{2, \ell+1}^{*}$ is greater than the utility of consuming their entire disposable income while they are working and relying on the benefits to finance their consumption. That is, cyclers choose to save if and only if

$$
\ln 0.5(1-\theta) w_{t}+\ln 0.5(1-\theta) w_{t}(1+r)>\ln (1-\theta) w_{t}+\ln b_{t+1} .
$$

Since $b_{t}=\mu^{-1}(1+n) \theta w_{t}$ and $w_{t}=(1+g) w_{t-1}$, this inequality condition implies that cyclers save if and only if

$$
\ln \left(\frac{1-\theta}{\theta}\right)>\ln x+2 \ln 2-\ln \mu .
$$

This inequality condition is important because it indicates the maximum value at which $\theta$ can be set in a means-tested program:

$$
\theta_{\max }=\frac{\mu}{\mu+4 x} .
$$

This maximum tax rate implies a maximum value for the ratio of the benefits paid to myopes (and therefore their level of retirement consumption) to the retirement consumption of cyclers. Since $b_{t}=$ $\mu^{-1} \theta(1+n) w_{t}$ and $C_{2, t}^{*}=0.5(1-\theta) w_{t-1}(1+r)$, the ratio of benefits to the retirement consumption of cyclers is

$$
\frac{b_{t}}{C_{2, t}^{*}}=\frac{\mu^{-1} \theta(1+n) w_{t}}{0.5(1-\theta) w_{t-1}(1+r)}=\frac{2 \theta x}{(1-\theta) \mu} .
$$

Substituting $\theta_{\max }$ from equation (5) yields $\left(b_{t} / C_{2, \ell}^{*}\right)_{\max }=0.5$. Thus the maximum level of benefits consistent with continued saving by the cyclers is one-half of the level of consumption that the cyclers would obtain by their optimal saving. While this simple result reflects the particular log-linear utility, it illustrates how the level of benefits may have to be constrained significantly in a means-tested program in order to keep cyclers saving.

The value of $\theta_{\max }$ increases with the relative number of myopes but less than proportionately, implying that the maximum benefits in a means-tested program vary inversely with the number of myopes. The value of $\theta_{\max }$ also varies inversely with $x$, implying that the maximum tax is reduced as the benefits produced by any level of tax increase. If the value $\theta^{*}$ that maximizes total utility on the assumption 
that cyclers save exceeds $\theta_{\max }$, the value $\theta^{*}$ is irrelevant and the feasible optimum value for a means-tested program is $\theta_{\max }{ }^{7}$

The analysis now proceeds by deriving, for different parameter combinations, the optimal tax value $\left(\theta^{*}\right)$ on the assumption that cyclers save. If $\theta^{*} \leqslant \theta_{\max }$, the total utility is calculated at $\theta^{*}$; if $\theta^{*}>\theta_{\max }$, total utility is calculated at $\theta_{\max }$. These total utility values for a meanstested program can then be compared with the total utility values for the universal program to decide whether the means-tested program or the universal program provides the higher level of total utility.

Total utility at time $t$ under the means-tested program can be written as the sum of the utilities of the $L_{t}$ workers and $L_{t-1}$ retirees:

$$
\begin{aligned}
W_{t}^{m}= & L_{t}\left[\mu \ln (1-\theta) w_{t}+(1-\mu) \ln 0.5(1-\theta) w_{t}\right] \\
& +L_{t-1}\left[\mu \ln b_{t}^{m}+(1-\mu) \ln 0.5(1-\theta)(1+r) w_{t-1}\right] .
\end{aligned}
$$

Substituting $b_{t}^{m}=\mu^{-1}(1+n) \theta w_{t}$ and $w_{t-1}=w_{t} /(1+g)$ shows once again that the same value of $\theta$ maximizes $W_{t}^{m}$ in each period. The firstorder condition for the means-tested program implies $\theta^{*}=\mu /(2+n)$ and, since $\beta_{m}^{*}=b_{t}^{m * / w_{t}}=\mu^{-1} \theta(1+n), \beta_{m}^{*}=(1+n) /(2+n)$. This result is very striking. It implies that the optimal benefit-wage ratio depends only on the rate of population growth and is independent of the frequency of myopes in the population and the relative efficiency of social security and real investment.

This striking conclusion is easily explained. A means-tested social security program is equivalent to a redistribution of income from all workers to those retirees who have no private assets. As such, it is a problem in optimal income redistribution. With no distorting effect of the tax or the benefit on labor supply or saving, ${ }^{8}$ the tax should be used to redistribute income until the marginal utility of a dollar of additional income for the working generation equals the marginal utility of a dollar to the retired myopes. The relative efficiency of private saving and social security at converting present to future income $(x)$ is irrelevant. And while the relative number of myopes influences the tax rate required to support the benefits, it does not alter the optimal level of benefits ( $\beta^{*}$ is independent of $\mu$ ).

When the constraint on $\theta^{*}$ is not binding, total utility for the meanstested program is always greater than total utility for the universal program. Although this apparently cannot be shown analytically be-

\footnotetext{
${ }^{7}$ A means-tested program in which cyclers do not save is, ex post, a universal program. Such a program is dominated by an ex ante universal program in which cyclers do some saving.

${ }^{B}$ The tax reduces the saving of the cyclers by reducing their disposable income, but there is no substitution effect distortion.
} 
cause the optimal value of $\theta$ for the universal program is defined only implicitly, it can be shown by calculating the optimal values of $\theta^{u}$ and $\theta^{m}$ and the resulting total utility measure numerically for all conceivable values of $\mu$ and $x(0 \leqslant \mu \leqslant 1.0$ and $0<x \leqslant 1.0)$ and for values of $n$ corresponding to annual population growth rates between zero and 3 percent $(0 \leqslant n \leqslant 1.43)$.

Even when the constraint on the optimal means-tested tax rate is binding $\left(\theta^{*}>\theta_{\max }\right)$, the total utility for the means-tested program may still be higher than total utility for the universal program. The universal program provides a higher level of total utility only when the constraint on the level of benefits given to the myopes in the meanstested program depresses their utility below what they would get in an optimal universal program by more than enough to outweigh the greater adverse effects on the cyclers of a universal program.

Explicit numerical calculations (Feldstein 1985b) show that the universal program is optimal only for high values of $x$ and relatively high values of $\mu$. Moreover, the greater the relative efficiency of social security (i.e., the higher the value of $x$ ), the lower is the relative frequency of myopes in the population at which the universal program becomes optimal. Note that, with the measure of social security efficiency $(x)$ that corresponds to U.S. experience of the past three decades, ${ }^{9}$ the universal program is not optimal for any value of $\mu$. This conclusion remains true for all rates of population growth.

This conclusion about the general dominance of the means-tested program depends, of course, on the simplified characterization of the population as either pure cyclers or pure myopes. In the richer model of the next section, there is more scope for a universal program to dominate.

\section{The Optimal Program When Benefits Distort Saving}

A social security program that pays means-tested benefits to only a fraction of retirees cannot distort saving in an economy with only two types of individuals. With only two types of individuals, the level of taxes and benefits can be set in a way that achieves perfect separation between myopes and cyclers. Myopes save nothing and depend on benefits, while cyclers save in a way that is not influenced by the level of potential benefits. Under these circumstances, a means-tested program will be optimal unless achieving separation requires a substantial restraint on the level of benefits.

\footnotetext{
9 The experience implies annual values of population growth of 1.4 percent, growth of real compensation per hour of 2.2 percent, and a pretax real return of 11.4 percent.
} 
In an economy with more than two types of individuals, a separation that does not distort saving is not always a characteristic of an optimal means-tested program. The analysis in this section shows that the optimal level of means-tested benefits may cause some individuals who are neither completely myopic nor perfectly rational life cycle utility maximizers to stop saving and rely exclusively on social security benefits. For these individuals, the reduction in saving is greater than it would be with a universal program. If they are sufficiently important in the population, the total utility of a means-tested program may be lower than the total utility of a universal program. The current analysis examines the characterization of the economy and of the population that influences this choice.

The analysis of the previous section can be extended to deal with this more general case by introducing a third class of individuals who are partially myopic, that is, who give too little weight to their future utility when they make savings decisions during their working years. More specifically, I will assume that a fraction $\Pi$ of the population acts during their working years to maximize $\ln C_{1}+\lambda \ln C_{2}$ with $\lambda<1$ even though their true lifetime utility is given by $\ln C_{1}+\ln C_{2}$. In Pigou's (1936) words, these partial myopes have a "faulty telescopic faculty" that causes them to give too little weight to future utility.

As before, it is useful to begin by analyzing the effects of a universal social security program and calculating the total utility level that results from an optimal universal program. The optimal means-tested program can then be derived and the resulting total utility level compared with that of the universal program.

\section{A. An Optimal Universal Social Security Program}

The budget constraint of a universal social security program is the same in the current three-class economy as it was in the simple economy of the previous section: $b_{t}=\theta(1+n) w_{t}$. The fundamental difference between the previous section and the current one lies in the behavior of the partial myopes. The partial myopes choose their firstperiod consumption by maximizing $\ln C_{1 t}+\lambda \ln C_{2, t+1}$ subject to the personal budget constraint $C_{2, t+1}=\left[(1-\theta) w_{t}-C_{1 t}\right](1+r)+b_{t+1}$. This implies first-period consumption of $C_{1 t}^{*}=(1+\lambda)^{-1}\left\{(1-\theta) w_{t}+\right.$ $\left.\left[b_{t+1} /(1+r)\right]\right\}$. Using the government budget constraint to eliminate $b_{t}$ and recalling that $x=(1+g)(1+n) /(1+r)$ measures the efficiency of social security, we can write the consumption of the partial myopes as $C_{1 t}^{*}=(1+\lambda)^{-1}(1-\theta+\theta x) w_{t}$ and $C_{2, t+1}^{*}=[\lambda /(1+\lambda)](1+r) w_{t}$. $(1-\theta+\theta x)$.

Although the partial myopes choose their consumption levels by maximizing $\ln C_{1 t}+\lambda \ln C_{2, t+1}$, the proper social valuation of the to- 
tal utility of the consumption of the partial myopes living at time $t$ is $\Pi L_{t} \ln \dot{C}_{1 t}^{*}+\Pi L_{t-1} \ln C_{2 t}^{*}$, where $\Pi$ is the fraction of partial myopes in the population. The consumption behavior and utility level of the pure myopes and the pure cyclers are the same as in the previous section. Total utility at time $t$ with the universal social security program can therefore be written as

$$
\begin{aligned}
W_{t}= & L_{t}\left[\mu \ln (1-\theta) w_{t}+\Pi \ln (1+\lambda)(1-\theta+\theta x) w_{t}\right. \\
& \left.+(1-\mu-\Pi) \ln 0.5(1-\theta+\theta x) w_{t}\right] \\
& +L_{t-1}\left[\mu \ln \theta(1+n) w_{t}\right. \\
& +\Pi \ln \left(\frac{\lambda}{1+\lambda}\right)(1+r)(1-\theta+\theta x) w_{t-1} \\
& \left.+(1-\mu-\Pi) \ln 0.5(1+r)(1-\theta+\theta x) w_{t-1}\right] .
\end{aligned}
$$

Substituting $w_{t}=(1+g) w_{t-1}$ and $L_{t}=(1+n) L_{t-1}$ and simplifying yields

$$
\begin{aligned}
W_{t}^{u}= & L_{t-1}[(1+n) \mu \ln (1-\theta)+\mu \ln \theta-(1-\mu) \ln x \\
& +(2+n)(1-\mu) \ln (1-\theta+\theta x)+\ln (1+n) \\
& -(2+n)(1-\mu-\Pi) \ln 2-(2+n) \Pi \ln (1+\lambda) \\
& +\Pi \ln \lambda]+L_{t-1}(2+n) \ln w_{t} .
\end{aligned}
$$

Consider now the value of $\theta$ that maximizes total utility with this universal program. Since the terms in equation (9) that include $\theta$ do not involve either $\Pi$ or $\lambda$, it follows immediately that the optimal value of $\theta$ is independent of the relative number of partial myopes or of their degree of myopia. It can be verified directly by differentiating $W_{t}^{u}$ with respect to $\theta$ that the optimal tax rate in the universal program satisfies

$$
\frac{\mu}{\theta^{*}}-\frac{(1+n) \mu}{1-\theta^{*}}-\frac{(2+n)(1-\mu)(1-x)}{1-(1-x) \theta^{*}}=0 .
$$

This is exactly the same as the optimum condition of equation (5) for an economy with no partial myopes. ${ }^{10}$

10 This simplifying property is a result of the log-linear nature of the utility function. It follows directly from the equations for consumption that changes in $\theta$ alter utility in a way that does not depend on the value of $\lambda$. The effect of $\theta$ on utility is therefore the same for partial myopes and for pure life-cyclers. Therefore, only the relative number of pure myopes is relevant to determining the optimal value of $\theta$. 


\section{B. A Means-tested Program with Partial Myopes}

A universal program of social security benefits reduces the saving of all individuals who save to finance future consumption, including both pure life-cyclers and partial myopes. ${ }^{11}$ In contrast, a meanstested program reduces saving only if it induces individuals to cut their saving in order to qualify for the means-tested benefit. In order to analyze this possibility, I will assume that benefits are provided only to individuals who do not save at all. ${ }^{12}$ Interest then focuses on the possibility that the partial myopes choose to stop saving and rely only on the benefits to finance retirement consumption. Since the level of benefits that induces such substitution may not be high enough to induce full life-cyclers to stop saving, the result may be a means-tested program in which only some retirees receive benefits but in which a substantial number of people substitute social security benefits for private saving.

The analysis that follows shows that the means-tested program may be preferred to a universal program even when partial myopes are induced to become nonsavers. Numerical calculations indicate that a means-tested program may be preferable to a universal program under a wide range of parameter values, although the possibility of inducing partial myopes to become nonsavers does increase the range of economic parameter values in which a universal program is preferred to a means-tested program. The implications of this are discussed more fully in the concluding section of the paper. But first the formal results must be derived and analyzed.

In the simpler case in which individuals are either pure myopes or pure cyclers, I derived the maximum value of $\theta$ that was consistent with continued saving by the cyclers. In the current context, two separate sets of conditions must be derived in order to evaluate total utility. In the first case, the value of $\theta$ is such that both the cyclers and the partial myopes continue to save. In the second case, the value of $\theta$ is such that only the cyclers continue to save and the partial myopes are induced to substitute benefits for private wealth accumulation. For each set of parameter values ( $\mu, x, n, \lambda$, and $\Pi$ ), both cases must be evaluated separately and the corresponding values of total utility cal-

11 This is in addition to the reduction in saving caused by the reduction in disposable income that results from the tax. The discussion in the remainder of the paragraph also ignores this tax effect and focuses on the substitution of benefits for private wealth accumulation.

${ }^{12}$ If the means-tested program provided full benefits to partial myopes, there would be no basis for analyzing the substitution of benefits for private saving. A more complex means-tested program that provided partial benefits to individuals with private assets but with less than a 100 percent effective tax rate would be worth analyzing- 
culated. The higher utility value indicates the optimum means-tested program. This total utility value can then be compared with the value of the corresponding universal program.

Consider first the conditions under which both cyclers and partial myopes save. Cyclers choose to save if and only if the utility that results from saving exceeds the utility of consuming all disposable income and relying on benefits to finance retirement consumption. This condition is exactly the same as equation (3) of Section I. Since in this case benefits are paid only to myopes, the government's budget constraint implies that $b_{t}=\mu^{-1} \theta(1+n) w_{t}$ and cyclers save only if $\theta$ is less than $\theta_{\max }^{c}=\mu /(\mu+4 x)$, just as in the previous section. This maximum value of $\theta$ is denoted $\theta_{\max }^{c}$ to emphasize that it is the highest value of $\theta$ consistent with saving by the cyclers.

The maximum value of $\theta$ that is consistent with continued saving by the partial myopes can be derived in a similar way. Partial myopes save only if the resulting lifetime utility (as they perceive it, with weight $\lambda$ given to second-period utility) exceeds the lifetime utility that results if all disposable income is consumed. This can be shown to imply that partial myopes save if and only if $\theta$ is less than

$$
\theta_{\max }^{\lambda}=\frac{\lambda \mu}{\lambda \mu+x(1+\lambda)^{(1+\lambda) / \lambda}},
$$

where the superscript $\lambda$ on $\theta_{\max }^{\lambda}$ indicates that this is the maximum value of $\theta$ consistent with continued saving by partial myopes. Differentiating this expression with respect to $\lambda$ shows that $\theta_{\max }$ rises monotonically with $\lambda$ for $0<\lambda \leqslant 1$. This means that $\theta<\theta_{\max }^{\lambda}$ implies $\theta<$ $\theta_{\max }^{c}$; if the value of $\theta$ is low enough to keep partial myopes saving, it is also low enough to keep cyclers saving.

I turn now to the second case in which the level of $\theta$ is high enough to cause partial myopes not to save but not so high that cyclers cease saving. The values of $\theta$ that define this range are not the values of $\theta_{\max }^{c}$ and $\theta_{\max }^{\lambda}$ that have just been derived because they were derived using the government budget constraint that holds when only the pure myopes are nonsavers. Since the current case corresponds to providing benefits to partial myopes as well as pure myopes, the government budget constraint becomes $b_{t}=(\mu+\Pi)^{-1} \theta(1+n) w_{t}$. It then follows directly that the values of $\theta$ that define the current range can be obtained by substituting $\mu+\Pi$ for $\mu$ in the previously derived expressions for $\theta_{\max }^{c}$ and $\theta_{\max }^{\lambda}$.

Selecting the value of $\theta$ that maximizes total utility in a means-tested program when only the pure myopes do not save (case 1 ) implies $\theta^{*}=$ $\mu /(2+n)$. This is exactly the same value of the optimal tax rate for the means-tested program that was obtained for the simpler structure in which there were no partial myopes. This is not surprising since, in 
the current case, the partial myopes continue to save and are therefore unaffected by the level of benefits.

Consider now the optimum value of $\theta$ in the second case in which only the cyclers save. In this case, it is easy to show that the first-order condition for the optimum tax rate in the means-tested program when partial myopes behave like pure myopes is $\theta^{*}=(\mu+\Pi) /(2+$ $n$ ). This is exactly analogous to the previously derived optimum tax rates for programs except that $\mu+\Pi$ now replaces $\mu$ because partial myopes behave like pure myopes.

Finally, it is possible that the value of $\theta$ derived on the assumption that only cyclers save will in fact cause even cyclers to want to stop saving. This limit on $\theta^{*}$ will be binding only if $\mu+\Pi+4 x \geqslant 2+n$. Although numerical calculations indicate that this is not binding for any $\mu$ and $\Pi$ at the historical values of $x$ and $n$, the constraint could be binding if social security were more efficient.

To summarize, there are three possible values of $\theta^{*}$ and the corresponding total utility values that must be examined in assessing the means-tested program. In the first case (only myopes do not save), $\theta^{*}$ $=\mu /(2+n)$, and the total utility is obtained by substituting this value into an equation for total social utility in which both cyclers and partial myopes make savings decisions. In the second case (both the myopes and the partial myopes do not save), $\theta^{*}=(\mu+\Pi) /(2+n)$, and total utility is obtained by substituting the value into a social utility equation in which only cyclers save. Finally, if both myopes and partial myopes do not save and $\theta$ must be set equal to the maximum value consistent with saving by the cyclers, $\theta^{*}=(\mu+\Pi) /(\mu+\Pi+4 x)$, and the total utility is obtained by substituting this value into an equation in which only cyclers save.

The social welfare ranking of universal and means-tested programs can be determined only by explicit evaluation of the total utility functions at the corresponding optimal values of $\theta$. These calculations, presented in Feldstein (1985b), indicate that, over a wide range of parameter values, a means-tested program is preferable to any universal program.

For example, with the social security efficiency parameter and the rate of population growth corresponding to U.S. experience of the past three decades, the universal program is optimal only for very low values of both $\lambda$ and $\mu$. Even when partial myopes give even as little weight to future utility as $\lambda=0.2$, the means-tested program is always optimal. But when the partial myopes weight future utility at only $\lambda=$ 0.1 , their implied saving rate is so low that an optimal means-tested program would cause partial myopes to stop saving. This is not a sufficient condition to make a universal program optimal, but if the partial myopes are also frequent enough in the population, the distor- 
tion of their saving does become important enough to outweigh the adverse effects of a universal program on the pure cyclers. Thus the universal program dominates when $\mu=0.1$ and $\Pi=0.2$ or $\mu=0.1$ and $\Pi=0.5$ and similarly when $\mu=0.2$ and $\Pi=0.5$.

Two things should be noted about these three combinations. First, it follows from the structure of the problem that if the universal program is optimal for $\mu=0.1$ and $\Pi=0.2$ and for $\mu=0.1$ and $\Pi=$ 0.5 , then the universal program is also optimal for all values of $\Pi \geqslant$ 0.2 if $\mu=0.1$. Note also that since the means-tested program is preferable at $\mu=0.1$ and $\Pi=0.1$, there is some value of $\Pi$ between 0.1 and 0.2 at which the universal program becomes optimal. Thus, for low enough $\lambda$ and $\mu$, the universal program is optimal as long as at least a modest fraction of the population are partial myopes.

Second, at $\mu=0.2$ the universal program is not optimal at $\Pi=0.2$ but becomes optimal at some value of $0.2<\Pi<0.5$. When there are more myopes, the optimal means-tested program becomes relatively more expensive and thus keeps the universal program optimal until the distortion of saving by the partial myopes becomes a more important problem, that is, until $\Pi$ reaches a higher level. For the same reason, when $\mu=0.5$ the mean-tested program is optimal at $\Pi=0.2$ and remains optimal until $\Pi \geqslant 0$.

When myopes put a higher value on future utility $(\lambda=0.2$ or $\lambda=$ 0.5 ), the partial myopes continue to save with the unconstrained optimal means-tested program. Under these conditions, the meanstested program dominates the universal program.

When the relative efficiency of social security $(x)$ increases, two things happen. First, under an optimal means-tested program, the partial myopes are more likely to stop saving and depend on the social security benefits. Second, although the means-tested program causes partial myopes to stop saving, the result is a smaller welfare loss when social security becomes relatively more efficient. As a result, the means-tested program remains preferable at moderate values of $\lambda$.

As $\lambda$ rises, the reduction in the saving of partial myopes caused by a means-tested program becomes large. In addition, with a high value of $\lambda=0.5$ and with $\Pi=0.5$, it is necessary to constrain the meanstested tax rate to avoid causing the cyclers to stop saving as well. In these cases, in which $\theta_{c}<\theta^{*}$ for the means-tested program, the universal program is optimal.

An optimal means-tested program is not always smaller than an optimal universal program. In some cases, both total taxes and therefore total benefits are higher under the optimal means-tested program than under the corresponding optimal universal program. Therefore, it cannot be said that a means-tested program is better because it is smaller, although for all the parameter values that $I$ 
studied the universal program is preferable only when it is also smaller than the corresponding optimal means-tested program.

\section{A Concluding Comment}

The analysis of this paper shows that a means-tested social security program may be preferable to a universal program under a wide range of economic conditions. But the analysis also shows that the optimal type of program and the optimal level of benefits in a universal program depend on the parameters that describe the population and the economy. For any combination of $\Pi$ and $\lambda$, an increase in the relative frequency of myopes raises the optimal tax in the meanstested program. Similarly, if the means-tested program is optimal but causes partial myopes to stop saving, the optimal tax rate increases with the combined frequency of myopes and partial myopes.

This suggests that overall welfare can be increased if the working population as a whole can be divided into two subgroups with a different type of program provided to each group. Note that this does not require that the subgroups be homogeneous-all cyclers or all myopes-but only that the groups have different mixes of myopes, partial myopes, and cyclers. Moreover, although it would obviously be best to know the characteristics of each subgroup with precision, a welcome improvement could be achieved even with imperfect information.

An obvious criterion for grouping individuals is income. Lowincome individuals are more likely to be myopes or to be partial myopes who give low weight to future consumption. If so, the lowincome group might be an appropriate candidate for a universal program.

The whole analysis in this paper has reflected the fact that the utility characteristics that influence the saving behavior of each individual are unobservable. It is possible, however, to observe saving. An individual who saves, especially in the form of a pension or special retirement account, is certainly not a myope in the sense of this paper. The analysis presented here implies that any individual who demonstrates sufficient saving should be eligible for a means-tested program even if a universal program would be optimal for that individual's population subgroup.

\section{References}

Abel, Andrew B. "Bequests and Social Security with Uncertain Lifetimes." Working Paper no. 1372. Cambridge, Mass.: N.B.E.R., 1984.

Barro, Robert J. "Are Government Bonds Net Wealth?" J.P.E. 82 (November/December 1974): 1095-1117. 
The Impact of Social Security on Private Saving: Evidence from the U.S. Time Series. Washington: American Enterprise Inst., 1978.

Blinder, Alan S.; Gordon, Roger H.; and Wise, Donald E. "Social Security Bequests and the Life Cycle Theory of Saving: Cross-sectional Tests." In The Determinants of National Savings and Wealth, edited by Franco Modigliani and Richard Hemming. London: Macmillan, 1983.

Danziger, Sheldon; Haverman, Robert; and Plotnick, Robert. "How Income Transfer Programs Affect Work, Savings, and the Income Distribution: A Critical Review." J. Econ. Literature 19 (September 1981): 975-1028.

Diamond, Peter A. "National Debt in a Neoclassical Growth Model." A.E.R. 55 (December 1965): 1126-50.

_ "A Framework for Social Security Analysis." J. Public Econ. 8 (December 1977): 275-98.

Diamond, Peter A., and Hausman, Jerry A. "Individual Retirement and Savings Behavior." J. Public Econ. 23 (February/March 1984): 81-114.

Feldstein, Martin S. "Social Security, Induced Retirement, and Aggregate Capital Accumulation." J.P.E. 82 (September/October 1974): 905-26. $630-42$.

- "The Optimal Level of Social Security Benefits." Q.J.E. 100 (May 1985): 303-20. (a)

- "Should Social Security Be Means Tested?" Working Paper no. 1775. Cambridge, Mass.: N.B.E.R., 1985. (b)

-. "The Welfare Cost of Social Security's Impact on Private Saving." In Essays in Honor of Arnold Harberger, edited by Michael Boskin. In press.

Friedman, Milton, and Cohen, W. Social Security: Universal or Selective? Washington: American Enterprise Inst., 1972.

Gustman, Alan, and Steinmeier, Thomas L. "Social Security Reform and Labor Supply." Working Paper no. 1212. Cambridge, Mass.: N.B.E.R., 1983.

Hubbard, R. Glenn. “' Precautionary' Saving Revisited: Social Security, Individual Welfare, and the Capital Stock." Working Paper no. 1430. Cambridge, Mass.; N.B.E.R., 1984.

Kotlikoff, Laurence J.; Spivak, Avia; and Summers, Lawrence H. "The Adequacy of Savings." A.E.R. 72 (December 1982): 1056-69.

Leimer, Dean R., and Lesnoy, Selig D. "Social Security and Private Saving: New Time-Series Evidence." J.P.E. 90 (June 1982): 606-29.

Munnell, Alicia H. The Effect of Social Security on Personal Savings. Cambridge, Mass.: Ballinger, 1974.

Pigou, Arthur C. The Economics of Welfare. London: Macmillan, 1936.

Samuelson, Paul A. "An Exact Consumption-Loan Model of Interest with or without the Social Contrivance of Money." J.P.E. 66 (December 1958): 467-82.

Sheshinski, Eytan, and Weiss, Yoram. "Uncertainty and Optimal Social Security Systems.” Q.J.E. 96 (May 1981): 189-206. 